now able to walk and run unaided. There are no involuntary movements. There is, however, a residual peripheral sensory neuropathy with generally slight reduction of power and absent tendon reflexes.

\section{Discussion}

Vitamin $B_{12}$ deficiency is rare in childhood; it usually occurs in breast fed infants of vitamin $B_{12}$ deficient mothers within the first year of life ${ }^{1}$ or in childhood pernicious anaemia. ${ }^{2}$ It may also be associated with extensive ileal resection, blind loops, and Crohn's disease. ${ }^{3}$ In our patient vitamin $B_{12}$ deficiency due to failure of active uptake of the vitamin $B_{12}$ intrinsic factor complex by the ileal mucosa was diagnosed by exclusion. This condition is commonly associated with proteinuria (Imerslund-Grusbeck syndrome) ${ }^{3}$ though this was absent in our patient.

Jadhav $^{1}$ describes florid, neurological manifestations of vitamin $B_{12}$ deficiency in infants, with involuntary movements and tongue fibrillation similar to that of our patient. To our knowledge, however, there is no other report documenting such severe neurological deterioration in childhood vitamin $B_{12}$ deficiency. Lambert, ${ }^{2}$ reviewing the clinical signs in juvenile pernicious anaemia, found no central nervous system abnormality in 7 of 9 patients and only absent reflexes and diminished vibration sense in the remaining two. He concluded that only anaemia, anorexia, vomiting, and diarrhoea were common to all patients.

There are neurological manifestations of vitamin $B_{12}$ deficiency in up to $90 \%$ of untreated patients. The peripheral neuropathy tends to be predominantly sensory. Computed cranial tomography may show non-specific atrophy but in most cases is normal. ${ }^{4}$ Necropsy studies show patchy degenera- tion of nerve fibres in both the brain and in the spinal cord. ${ }^{5}$

Folate may induce temporary haematological remission in vitamin $B_{12}$ deficiency but may also precipitate sudden and rapid neurological deterioration. ${ }^{6}$ Our patient received large doses of supplementary folate while in Bangladesh and this may have contributed to the severity of her illness.

In adult pernicious anaemia early treatment with parenteral vitamin $B_{12}$ within the first three to 6 months of the onset of symptoms leads to resolution of most of the neurological deficit, improvement occurring largely within the first 6 months. ${ }^{4}$ Our patient has shown steady improvement since diagnosis. There is no evidence of mental retardation, although this has been reported. ${ }^{2}$ Her potential for continuing recovery is possibly greater than that of the classic, adult patient with pernicious anaemia despite the late introduction of treatment and the previous folate treatment.

Investigation of obscure neurological disease in childhood should include a vitamin $B_{12}$ assay even when the blood count is normal.

\footnotetext{
References

1 Jadhav M, Webb JKG, Vaishnava S, Baker SJ. Vitamin $B_{12}$ deficiency in Indian infants. Lancet 1962;ii:903-7.

2 Lambert HP, Prankerd TAJ, Smellie JM. Pernicious anaemia in childhood. $Q J$ Med 1961;30:71-90.

${ }^{3}$ Matthews DM, Linnell JC. Cobalamin deficiency and related disorders in infancy and childhood. EurJ Pediatr 1982;138:6-16.

4 Roach E. Neurological disease of vitamin $\mathrm{B}_{12}$ deficiency. Am Fam Physician 1982;25:111-5.

5 Adams RD, Kubik CS. Sub-acute degeneration of the brain in pernicious anaemia. $N$ Engl $J$ Med 1944;231:1-8.

6 Ross JS, Belving H, Paegel BL. The development and progression of sub-acute combined degeneration of the spinal cord in patients with pernicious anaemia treated with synthetic pteroylglutamic (folic) acid. Blood 1948:3:68-89.
}

Correspondence to Dr J M Littlewood, St James's University Hospital, Becket Street, Leeds.

Received 20 February 1984

\title{
Achalasia of the oesophagus presenting as foreign body obstruction
}

\author{
A PATRICK, I W CAMPBELL, M S FRASER, D H K SMITH, AND P R WALBAUM \\ Departments of Medicine, Paediatrics, and Radiology, Victoria Hospital, Kirkcaldy and Department of \\ Thoracic Surgery, City Hospital, Edinburgh
}

SUMMARY A 15 year old boy with profound weight
loss was found to have foreign body obstruction of
the lower oesophagus. Achalasia was subsequently
diagnosed and there was rapid gain in weight and
height after oesophagomyotomy.
Achalasia of the oesophagus is a rare disease in children. The overall incidence is approximately $1 / 100000^{1}$ with only some 4 to $5 \%$ reporting symptoms under the age of 14 years. ${ }^{23}$ Almost all patients with achalasia present with dysphagia. ${ }^{4}$ Regurgitation, retrosternal pain, weight loss, and 
respiratory problems also occur, with the latter two being more common in children. ${ }^{2-5}$

We report a boy with achalasia of the oesophagus in whom the presenting symptom of profound weight loss was initially thought to be due to simple foreign body obstruction of the oesophagus.

\section{Case history}

A boy aged 15 years and 2 months was admitted to hospital with a 6 month history of weight loss which had been especially noticeable over the three weeks before presentation. He had no gastrointestinal symptoms. His past history included recurrent respiratory symptoms which had been diagnosed as 'chest infection' and treated empirically with antibiotics on several occasions. At the age of 4 years and 3 months he had swallowed an old 'halfpenny' coin of diameter $25 \mathrm{~mm}$ which was removed from the middle third of the oesophagus during oesophagoscopy. His growth and development had been well documented in school and hospital medical records and his weight had steadily fallen against the mean. At 2 years and 11 months of age his weight was $13 \mathrm{~kg}$ (25th centile); at 11 years his weight was $23.5 \mathrm{~kg}$ (third centile); and at 13 years and 1 month his weight was $26 \mathrm{~kg}$ (third centile). His history of actual weight loss, however, was relatively short. At presentation his weight was $22 \mathrm{~kg}$ and his height was $145 \mathrm{~cm}$. Apart from noticeable cachexia there were no abnormal findings. Routine biochemical and haematological investigations were normal.

The patient was subsequently noted to vomit on a number of occasions after meals and a barium swallow showed dilatation of the oesophagus to a diameter of $7 \mathrm{~cm}$ with apparent obstruction to the passage of the contrast at the level of the gastrooesophageal junction. Two coins were also noted, impacted towards the lower end of the oesophagus (Figure, left). The patient had no recollection of swallowing any coins. Oesophagoscopy showed that the lower end of the oesophagus was obstructed by a combination of two 'two pence' coins $(25 \mathrm{~mm}$ diameter), four whole peas, and a variety of food debris. After the removal of these foreign objects, the gastro-oesophageal junction seemed normal and readily admitted a 28 guage bougie.

The patient subsequently remained asymptomatic and began to regain weight. Six months later his weight was up to $32 \mathrm{~kg}$. A chest radiograph, however, showed a widely dilated mediastinum with an oesophageal fluid level (Figure, right) and a further barium swallow showed that the oesophagus was now dilated to a diameter of $10 \mathrm{~cm}$. Obstruction was again evident at the gastro-oesophageal junction and the radiographic appearance was that of achalasia of the oesophagus. ${ }^{4}$ Repeat oesophagoscopy showed a grossly dilated oesophagus with considerable food residue and tight contraction of the gastro-oesophageal sphincter. An oesophagomyotomy was performed and the patient has remained well. Twenty six months after surgery his weight was $53 \mathrm{~kg}$ (10th centile), his height was 169 $\mathrm{cm}$, and a barium swallow at this time showed free passage of contrast through the gastro-oesophageal sphincter.
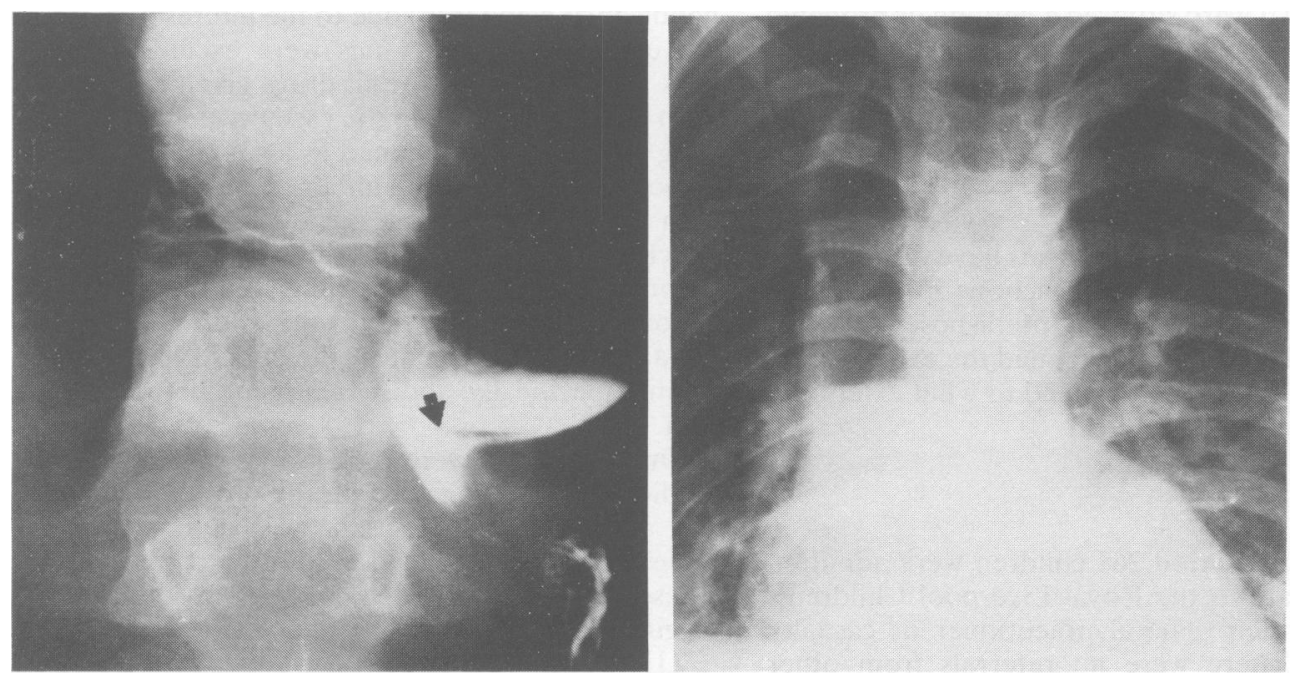

Figure Left, two 'two pence' coins lying in horizontal plane impacted at the lower end of the dilated oesophagus and right. widely dilated mediastinum with oesophageal fluid level. 


\section{Discussion}

There are several points which are unusual. The presence of recurrent respiratory symptoms in association with a gradual fall in weight against the mean over a period of years suggest that achalasia may have been present from a very early age. It is most unusual, in view of the fact that severe achalasia was present radiologically, that there were so few gastrointestinal symptoms, although achalasia presenting with weight loss or respiratory symptoms alone is recognised. ${ }^{5}$ Of particular interest is the fact that the achalasia was present in association with foreign body obstruction of the oesophagus. The history of actual weight loss was relatively short and as the patient gained weight steadily after the removal of the foreign objects, without further treatment, it would seem that it was the obstruction superimposed on the underlying pathology of achalasia of the oesophagus which was responsible for the rapid deterioration.
We thank Miss H Clark and Mr W R D MacIntyre of the Medical Photography Department for the Figures and Mrs M Frew and Miss W Cairns for secretarial help.

\section{References}

' Ellis FH, Jr, Olsen AM. Achalasia of the oesophagus. In: Dunphy JE, ed. Major problems in clinical surgery vol IX. Philadelphia: WB Saunders. 1969:65-104.

2 Sorsdahl OA, Gay BB, Jr. Achalasia of the oesophagus in children. Am J Dis Child 1965;109:141-6.

${ }^{3}$ Swenson O, Oeconomopoulos CT. Achalasia of the oesophagus in children. J Thorac Cardiovas Surg 1961:41:49-59.

${ }^{4}$ Olsen AM, Holman CB, Andersen HA. The diagnosis of cardiospasm. Diseases of the Chest 1953;23:477-97.

5 Schultz EH, Jr. Achalasia in children as a cause of recurrent pulmonary disease. J Pediatr 1961;59:522-8.

Correspondence to Dr I W Campbell, Consultant Physician, Victoria Hospital, Hayfield Road, Kirkcaldy, Fife, KY2 5AH.

Received 22 February 1984

\title{
Adverse drug reactions in medical inpatients
}

\author{
I A CHOONARA AND F HARRIS \\ Royal Liverpool Children's Hospital, Liverpool
}

\begin{abstract}
SUMmary Fifteen of 268 children admitted to a general medical ward suffered a definite or probable adverse drug reaction to their treatment. In 6 of these children the reactions were preventable. Anticonvulsants were the most common cause of an adverse reaction.
\end{abstract}

Several studies (mostly American) have investigated the extent of adverse drug reactions in paediatric inpatients and factors that predispose to drug reactions. ${ }^{1-3}$ This study determined the extent of the problem in a British hospital and to what extent the reactions were preventable.

\section{Subjects and methods}

Over a 6 month period 268 children were admitted for medical care to the Royal Liverpool Children's Hospital via their general practitioner or casualty department. There were no referrals from other hospitals requiring a specialist opinion. All the children were suffering from illnesses of a general medical nature, although there was a slight bias towards patients with neurological disorders (mental handicap and epilepsy) due to the interests of one of the consultants. Poisonings were excluded.

A record was kept of all drugs given in hospital, both on the ward and in the casualty department. A drug was arbitrarily defined as a substance that had to be prescribed by a member of the medical staff, with the exception of intravenous fluids and oxygen which were excluded from the survey. Drugs given before hospital admission were determined by (1) history from the parents, (2) the referral letter, and (3) a questionnaire sent to the general practitioner asking specifically about treatment before admission.

Drug reactions were looked for prospectively by medical and nursing staff on the daily ward round. An adverse drug reaction was defined as any undesired or unintended response to medication. These were classified according to the criteria originally used by Seidl et al. ${ }^{4}$

(1) Definite; directly attributable to a drug, having a clear temporal relation to drug administration and confirmed by positive rechallenge or 